\title{
FAKTOR RISIKO TERJADINYA PENYAKIT JANTUNG KORONER \\ PADA PASIEN DI UNIT RAWAT JALAN RUMAH SAKIT PANTI RAPIH YOGYAKARTA
}

\author{
Deviana Widayanti ${ }^{1}$, Chatarina Setya Widyastuti ${ }^{2}$ \\ ${ }^{1}$ Rumah Sakit Panti Rapih Yogyakarta, mrdeviana@gmail.com \\ ${ }^{2}$ STIKes Panti Rapih Yogyakarta, chatrin.sw@gmail.com
}

\begin{abstract}
ABSTRAK
Latar Belakang: Penyakit Jantung Koroner atau yang biasa disebut PJK adalah suatu kondisi ketika arteri yang mensuplai darah untuk dinding jantung mengalami pengerasan dan penyempitan. Penyakit jantung koroner diperkirakan $30 \%$ menjadi penyebab kematian di seluruh dunia.

Tujuan: Penelitian ini bertujuan untuk mengetahui faktor risiko PJK di RS Panti Rapih.

Metode: Penelitian deskriptif ini bertujuan mengetahui faktor risiko PJK di unit rawat jalan RS Panti Rapih. Populasinya adalah pasien yang telah didiagnosa Penyakit Jantung Koroner dan sampel diambil 50 responden dengan teknik non random acidental sampling. Instrumen yang digunakan adalah kuesioner faktor risiko terjadinya penyakit jantung koroner. Analisa dilakukan secara univariat.

Hasil: Faktor risiko terjadinya PJK adalah faktor yang tidak dapat diubah yaitu riwayat penyakit pada keluarga sejumlah $42 \%, 95 \%$ pada pria berusia $\geq 40$ tahun dan $95 \%$ pada wanita berusia $\geq 65$ tahun. Faktor yang dapat diubah sejumlah: kebiasaan merokok $78 \%$, riwayat hipertensi $68 \%$, riwayat diabetes mellitus $28 \%$, dislipidemi $90 \%$, berat badan berlebih $42 \%$ dan kurang olah raga 38\%.

Simpulan: Faktor risiko PJK yang tidak dapat diubah yaitu: riwayat penyakit pada keluarga sejumlah $42 \%, 95 \%$ pada pria berusia $\geq 40$ tahun dan $95 \%$ pada wanita berusia $\geq 65$ tahun. Faktor yang dapat diubah yaitu: Kebiasaan merokok $78 \%$, riwayat hipertensi $68 \%$, riwayat Diabetes mellitus $28 \%$, dislipidemi $90 \%$, berat badan berlebih $42 \%$ dan kurang olah raga $38 \%$.
\end{abstract}

Kata kunci: penyakit jantung koroner, faktor risiko 
Faktor Risiko Terjadinya Penyakit Jantung Koroner pada Pasien di Unit Rawat Jalan Rumah Sakit Panti Rapih Yogyakarta

\begin{abstract}
Background: Coronary Heart Disease (CHD) Is a condition when the arteries that supply blood to the heart wall experience hardening and narrowing. It is estimated that $30 \%$ of coronary heart disease causes death worldwide.

Objective: This study aims to determine the risk factors for CHD in Panti Rapih Hospital.

Methods: This descriptive study aims to determine the risk factors for CHD in outpatients at Panti Rapih Hospital. The population is patients who have been diagnosed with coronary heart disease and the sample was taken by 50 respondents with non-random accidental sampling technique. This research take the data use questionnaire and make univariat analysis.

Results: Risk factors for CHD are a number of factors that cannot be changed: family history of $42 \%$, age $\geq 40$ years $95 \%$ in men and $95 \%$ age $\geq 65$ years in women. Factors that can be changed are: Smoking 78\%, history of hypertension $68 \%$, history of diabetes mellitus $28 \%$, dyslipidemic $90 \%$, excess body weight $42 \%$ and lack of exercise $38 \%$.

Conclusion: Risk factors for CHD that cannot be changed: family history of $42 \%$, age $\geq 40$ years $95 \%$ in men and $95 \%$ age $\geq 65$ years in women. Factors that can be changed are: Smoking $78 \%$, history of hypertension $68 \%$, history of diabetes mellitus $28 \%$, dyslipidemic $90 \%$, excess body weight $42 \%$ and lack of exercise $38 \%$.
\end{abstract}

Keywords: coronary heart disease, risk factors

\title{
PENDAHULUAN
}

Penyakit Jantung Koroner

atau yang biasa disebut PJK adalah ketika arteri yang mensuplai darah untuk dinding jantung mengalami pengerasan dan penyempitan. Hal ini mengakibatkan berkurangnya pasokan oksigen dan zat gizi ke jaringan miokard karena terbatasnya aliran darah koroner (Robinson \& Saputra, 2014).
Menurut Framingham Heart Study, USA suatu institusi yang terkenal dalam penyakit kardiovaskuler, mereka berpendapat bahwa PJK bukanlah penyakit manusia lanjut usia (manula) atau nasib buruk yang tidak dapat dihindari. Untuk itu terdapat beberapa faktor risiko yang digolongkan menjadi dua yaitu 
faktor yang dapat diubah (kebiasaan merokok, hipertensi, DM, dislipidemia, kegemukan, kurang aktivitas fisik) dan faktor yang tidak dapat diubah (riwayat keluarga, usia, jenis kelamin) (Supriyono, 2008).

Penyakit Jantung Koroner (PJK) telah menjadi penyebab kematian utama di dunia maupun di Indonesia. Banyak orang terkena serangan jantung tanpa ada gejala apapun sebelumnya. Selama 50 tahun terakhir, semakin banyak orang terkena penyakit jantung koroner. Penyakit jantung koroner diperkirakan $30 \%$ menjadi penyebab kematian di seluruh dunia. American Heart Association (AHA) pada tahun 2004 memperkirakan prevalensi penyakit jantung koroner di Amerika Serikat sekitar 13.200.000 (Zahrawardani, Herlambang, \& Anggraheny, 2013). Hasil Riset Kesehatan Dasar (Riskesdas) 2013 menunjukkan prevalensi jantung koroner berdasarkan wawancara terdiagnosis dokter di Indonesia sebesar 0,5 persen. Prevalensi jantung koroner tertinggi berada di Sulawesi Tengah $(0,8 \%)$ diikuti Sulawesi Utara, DKI
Jakarta, Aceh masing-masing 0,7 persen. Sementara prevalensi jantung koroner menurut diagnosis atau gejala tertinggi di Nusa Tenggara Timur (4,4\%), diikuti Sulawesi Tengah (3,8\%), Sulawesi Selatan (2,9\%), dan Sulawesi Barat $(2,6 \%)$. Prevalensi penyakit jantung koroner (PJK) berdasarkan wawancara yang didiagnosa dokter gejala meningkat seiring dengan bertambahnya umur, tertinggi pada kelompok umur 65 -74 tahun yaitu $2,0 \%$ dan 3,6\%, menurun sedikit pada kelompok umur $\geq 75$ tahun. Prevalensi PJK yang didiagnosa dokter maupun berdasarkan diagnosis dokter atau gejala lebih tinggi pada perempuan $0,5 \%$ dan 1,5\%). Prevalensi PJK lebih tinggi pada masyarakat tidak bersekolah dan tidak bekerja. Pada Riskesdas 2018, terjadi perubahan prevalensi pada prevalensi penyakit jantung berdasar diagnosis dokter yang tertinggi yaitu Kaltara, dilanjutkan Gorontalo dan DIY pada posisi ketiga. Terbanyak di perkotaan dan pada perempuan (Riskesdas 2018).

Sementara itu berdasarkan data yang diperoleh dari Rekam 
Faktor Risiko Terjadinya Penyakit Jantung Koroner pada Pasien di Unit Rawat Jalan Rumah Sakit Panti Rapih Yogyakarta

Medik Rumah Sakit Panti Rapih Yogyakarta pasien yang mengalami Penyakit Jantung Koroner dari tahun 2014-2017 sebanyak 1157 pasien atau rata rata sekitar 32 pasien per bulan yang dirawat dan sebanyak 4467 pasien atau rata rata sekitar 125 pasien per bulan yang menjalani rawat jalan di Poliklinik Jantung Rumah Sakit Panti Rapih Yogyakarta. Sedangkan pada bulan Januari sampai bulan September 2017 didapatkan jumlah penderita Penyakit Jantung Koroner sebanyak 612 pasien atau rata rata sekitar 68 pasien per bulan yang dirawat dan sebanyak 888 atau rata rata sekitar 98 pasien per bulan yang menjalani rawat jalan di Poliklinik Jantung Rumah Sakit Panti Rapih Yogyakarta. Hal ini menunjukkan peningkatan pasien yang dirawat di Rumah Sakit dengan PJK.

Penyakit jantung koroner merupakan masalah kesehatan masyarakat yang penting karena morbiditas (kesakitan) dan mortalitas (kematian) yang tinggi. Ditinjau dari segi pembiayaan, akibat waktu perawatan dan biaya pengobatan penyakit jantung koroner serta pemeriksaan penunjangnya, tentu tidak sedikit. Belum lagi keberhasilan pengobatan sangat bergantung kepada kecepatan penanganan penyakit. Oleh karena itu, upaya pencegahan PJK sangat bermanfaat karena sudah pasti lebih murah dan lebih efektif. Hal ini dapat ditempuh dengan salah satu cara diantaranya yaitu mengenali faktor risiko penyakit dan berperilaku hidup sehat. Karena sampai sekarang penyebab PJK secara pasti belum diketahui.

Peran perawat sebagai pemberi edukasi sangat diperlukan dalam upaya pencegahan PJK tersebut. Apabila faktor risiko dapat diketahui maka akan lebih mudah untuk dilakukannya pencegahan. Karena bagaimanapun mencegah lebih baik daripada mengobati. Dalam rangka pencegahan tersebut perlu dikenali faktor risiko yang berpengaruh terhadap kejadian PJK seperti kebiasaan merokok, riwayat hipertensi, riwayat diabetes melitus, berat badan berlebih, kurang aktivitas fisik, dislipidmia, jenis kelamin, usia dan riwayat keluarga. Melihat banyaknya kejadian 
Penyakit Jantung Koroner ini, maka penting sekali diketahui gambaran tentang apa saja faktor risiko terjadinya PJK. Untuk itu, penting dilakukan penelitian tentang faktor risiko terjadinya penyakit jantung koroner pada pasien PJK di unit rawat jalan Rumah Sakit Panti Rapih Yogyakarta.

\section{Rumusan Masalah}

Apakah faktor risiko terjadinya Penyakit Jantung Koroner pada pasien PJK di rawat jalan Rumah Sakit Panti Rapih Yogyakarta?

\section{Tujuan Penelitian}

Penelitian ini dimaksudkan untuk mendapatkan gambaran tentang faktor risiko terjadinya Penyakit Jantung Koroner pada pasien PJK di unit rawat jalan Rumah Sakit Panti Rapih Yogyakarta.

\section{METODE PENELITIAN}

\section{Desain Penelitian}

Jenis penelitian ini adalah penelitian kuantitatif dengan pendekatan survey deskriptif yaitu suatu metode penelitian yang dilakukan dengan tujuan memperoleh gambaran tentang faktor risiko terjadinya Penyakit Jantung Koroner pada pasien PJK di unit rawat jalan Rumah Sakit Panti Rapih Yogyakarta. Instrumen yang digunakan adalah kuesioner.

\section{Populasi dan Sampel}

Populasi pada penelitian ini adalah semua pasien penderita penyakit jantung koroner yang mengunjungi unit rawat jalan Poli Jantung Rumah Sakit Panti Rapih Yogyakarta pada bulan November sampai Desember 2017.

Teknik pengambilan sampel dengan non random acidental sampling selama periode penelitian kurang lebih selama satu bulan. Jumlah sampel dalam penelitian ini adalah 50 responden yang sudah menandatangani informed consent.

\section{Alat dan Prosedur Pengumpulan Data Instrumen dalam penelitian ini adalah kuesioner yang dikembangkan oleh peneliti dan telah dilakukan uji validitas isi}


melalui konsultasi pembimbing serta dilakukan uji validitas dan reliabilitas dengan hasil alpha cronbach $>0,6$. Pengumpulan data dilakukan oleh peneliti melalui wawancara langsung pada subjek penelitian sesuai pertanyaan dalam kuesioner atau responden mengisi langsung kuesioner yang diberikan.

\section{Analisis Data}

Analisa Univariat

Analisis data univariat digunakan untuk menyajikan data terkait data faktor risiko terjadinya PJK pada pasien PJK di unit rawat jalan RS Panti Rapih Yogyakarta.

\section{HASIL DAN PEMBAHASAN}

\section{Analisis Univariat \\ Faktor Risiko yang Tidak Dapat Diubah}

Berdasarkan tabel 1 berikut dapat diketahui bahwa sebagian besar 36 responden (95\%) mengalami PJK pada usia $\geq 40$ tahun untuk pria dan sebagian kecil sejumlah 2 responden (5\%) mengalami PJK $<40$ tahun untuk pria. Sedangkan pada wanita, lebih dari separuh 7 responden (58\%) PJK di usia $\geq 65$ tahun dan kurang dari separuh sejumlah 5 responden (42\%) mengalami PJK di usia $<65$ tahun. Jenis kelamin diketahui bahwa sebagian besar 38 responden (76\%) adalah laki - laki dan sebagian kecil 12 responden (24\%) adalah wanita. Riwayat keluarga diketahui bahwa kurang dari separuh 21 responden (42\%) memiliki riwayat keluarga dengan PJK dan lebih dari separuh 29 responden (58\%) tidak memiliki riwayat keluarga dengan PJK.

\section{Tabel 1}

Distribusi Frekuensi Faktor Risiko yang Tidak Dapat Diubah

\begin{tabular}{|c|c|c|c|}
\hline Faktor risiko & & $\mathrm{f}$ & $\%$ \\
\hline Usia & $\geq 65$ tahun & 7 & 58 \\
\hline \multirow[t]{2}{*}{ Wanita } & $<65$ tahun & 5 & 42 \\
\hline & Total & 12 & 100 \\
\hline \multirow[t]{3}{*}{ Pria } & $\geq 40$ tahun & 36 & 95 \\
\hline & $<40$ tahun & 2 & 5 \\
\hline & Total & 38 & 100 \\
\hline \multicolumn{2}{|l|}{ Total } & 50 & 100 \\
\hline Jenis & Wanita & 12 & 24 \\
\hline kelamin & Pria & 38 & 76 \\
\hline \multicolumn{2}{|l|}{ Total } & 50 & 100 \\
\hline \multirow{3}{*}{$\begin{array}{l}\text { Riwayat } \\
\text { penyakit } \\
\text { PJK dalam } \\
\text { keluarga }\end{array}$} & & & \\
\hline & Tidak & 29 & 58 \\
\hline & & & \\
\hline \multicolumn{2}{|l|}{ Total } & 50 & 100 \\
\hline
\end{tabular}

Sumber: data primer 
Faktor Risiko Dapat Diubah

Tabel 2

Distribusi Frekuensi Faktor Risiko yang Dapat Diubah

\begin{tabular}{|c|c|c|}
\hline Faktor risiko & $\mathrm{f}$ & $\%$ \\
\hline $\begin{array}{l}\text { Kebiasaan } \\
\text { merokok }\end{array}$ & & \\
\hline Ya & 39 & 78 \\
\hline Tidak & 11 & 22 \\
\hline Total & 50 & 100 \\
\hline $\begin{array}{l}\text { Riwayat } \\
\text { hipertensi }\end{array}$ & & \\
\hline Ya & 34 & 68 \\
\hline Tidak & 16 & 32 \\
\hline Total & 50 & 100 \\
\hline $\begin{array}{l}\text { Menderita } \\
\text { Diabetes } \\
\text { Melitus }\end{array}$ & & \\
\hline Ya & 14 & 28 \\
\hline Tidak & 36 & 72 \\
\hline Total & 50 & 100 \\
\hline Dislipidmia & & \\
\hline Ya & 45 & 90 \\
\hline Tidak & 5 & 10 \\
\hline Total & 50 & 100 \\
\hline BMI $>25$ & & \\
\hline Ya & 21 & 42 \\
\hline Tidak & 29 & 48 \\
\hline Total & 50 & 100 \\
\hline $\begin{array}{l}\text { Kurang } \\
\text { aktivitas fisik }\end{array}$ & & \\
\hline Ya & 31 & 62 \\
\hline Tidak & 50 & 100 \\
\hline Total & & \\
\hline Sumber & & \\
\hline
\end{tabular}

Sumber: data primer

Berdasarkan tabel 2 diatas menunjukkan bahwa faktor risiko yang tidak dapat diubah terdiri dari kebiasaan merokok diketahui bahwa sebagian besar sejumlah 39 responden $(78 \%)$ memiliki kebiasaan merokok. Riwayat hipertensi diketahui bahwa lebih dari separuh sejumlah 34 responden (68\%) memiliki riwayat hipertensi. Lebih dari separuh sejumlah 36 responden $(72 \%)$ tidak memiliki riwayat diabetes melitus sebelumnya Sebagian besar sejumlah 45 responden $(90 \%) \quad$ memiliki dislipidmia tinggi. Lebih dari separuh sejumlah 29 responden (49\%) memiliki BMI kurang dari 25 atau masih dalam rentang normal yaitu 21-25 dan kurang dari separuh sejumlah 21 responden (42\%) memiliki BMI atau Body Mass Index $>25$. Lebih dari separuh sejumlah 31 responden (62\%) dengan PJK melakukan aktivitas fisik yang menyehatkan badan seperti olahraga.

\section{PEMBAHASAN}

Faktor Risiko yang Tidak Dapat Diubah

a. Riwayat Keluarga

Berdasarkan penelitian diketahui bahwa tidak sampai separuh sejumlah 21 responden (42\%) memiliki riwayat keluarga dengan PJK. Riwayat keluarga dengan PJK dapat diturunkan 
Faktor Risiko Terjadinya Penyakit Jantung Koroner pada Pasien di Unit Rawat Jalan Rumah Sakit Panti Rapih Yogyakarta

melalui orangtua, kakek-nenek dan saudara kandung. Hasil penelitian Supriyono (2008) juga mengatakan bahwa riwayat keluarga menderita PJK mempunyai risiko 1,75 kali lebih besar untuk menderita PJK dan wanita dengan riwayat keluarga menderita PJK mempunyai risiko 1,83 kali lebih besar untuk menderita PJK dibandingkan dengan yang tidak mempunyai riwayat PJK. Hal ini menunjukkan bahwa seseorang yang memiliki riwayat keluarga dengan penyakit PJK lebih berisiko menderita PJK.

Berdasarkan analisis

multivariate dalam penelitian Andarmoyo dan Nurhayati (2014) menunjukkan bahwa faktor-faktor yang berpengaruh terhadap kejadian PJK adalah Jenis Kelamin $(\mathrm{p}=0,032<0,050 ; \quad \mathrm{OR}=6,4 ;$ $\mathrm{CI}=95 \%$ ), dan Riwayat Keturunan $(\mathrm{p}=0,003<\quad 0,050 ; \quad \mathrm{OR}=11,2 ;$ $\mathrm{CI}=95 \%$ ).

Berbeda dengan hasil penelitian ini yang menunjukkan lebih banyak penderita PJK yang tidak memiliki riwayat penyakit keluarga dengan PJK. Hal ini dimungkinkan karena jumlah responden yang kurang banyak atau responden atau keterbatasan peneliti dalam menggali lebih dalam tentang riwayat penyakit keluarga yang bisa terjadi sampai 3 generasi diatasnya mengingat responden dalam penelitian ini mayoritas berada pada usia pralansia dan lansia.

\section{b. Usia}

Berdasarkan hasil penelitian sebagian besar sejumlah 36 responden (95\%) dengan PJK mengalami PJK pada kelompok usia $\geq 40$ tahun untuk pria. Sedangkan pada wanita, menunjukan lebih dari separuh sejumlah 7 responden (58\%) dengan PJK mengalami PJK di usia $\geq 65$ tahun. Hasil penelitian ini sesuai dengan penelitian Nababan (2008) bahwa aterosklerosis berawal dari usia muda dan perlahan-lahan menjadi lebih banyak pada usia dewasa yang selanjutnya akan mendorong terjadinya penyumbatan arteri. Selain itu, menurut Supranto (2009) "Semakin bertambah umur, 
semakin terasa adanya penyakitpenyakit hingga adanya disfungsi organ tubuh tertentu. Inilah yang disebut penyakit degenaratif".

Menurut asumsi dari peneliti, usia dianggap berisiko terhadap PJK dikarenakan semakin tua usia seseorang maka semakin tua pula bagian organ tubuhnya akibatnya semakin menurun kemampuan organ tersebut untuk berfungsi secara optimal dan jika dikombinasikan dengan faktor genetik serta faktor lain, maka hal itu berpotensial meningkatkan terjadinya PJK.

c. Jenis Kelamin

PJK adalah penyebab nomor satu kematian pada orang dewasa dari negara berpenghasilan rendah, menengah dan tinggi. Pada pergantian abad, dilaporkan bahwa kematian CHD diperkirakan meningkat sekitar $29 \%$ pada wanita dan $48 \%$ pada pria di negara maju antara tahun 1990 dan 2020; estimasi kenaikan yang sesuai di negara berkembang adalah $120 \%$ pada wanita dan
137\% pada pria (Sanchis, Perez., Leischik, \& Lucia, 2016). Berdasarkan hasil penelitian sebagian besar sejumlah 38 responden (76\%) dengan PJK adalah laki-laki. Laki-laki dikatakan lebih berisiko menderita PJK karena gaya hidup laki-laki yang cenderung lebih bebas dari wanita. Selain itu sejalan dengan penelitian dari Supriyono (2008) menyatakan bahwa hormon estrogen pada wanita memberikan berbagai efek melindungi terhadap faktor risiko PJK seperti dapat meningkatkan kolesterol baik (HDL) dan menurunkan kolesterol jahat (LDL). Namun setelah menopause risiko terjadinya PJK pada jenis kelamin wanita dan laki-laki sama karena tidak ada lagi hormon estrogen yang secara alamiah melindungi wanita dari PJK.

\section{Faktor Risiko yang Dapat Diubah}

a. Kebiasaan Merokok

Berdasarkan sebagian besar sejumlah 39 responden (78\%) dengan PJK memiliki kebiasaan 
Faktor Risiko Terjadinya Penyakit Jantung Koroner pada Pasien di Unit Rawat Jalan Rumah Sakit Panti Rapih Yogyakarta

merokok. Kebiasaan merokok dikatakan berisiko karena nikotin pada rokok akan merusak dinding pembuluh darah yaitu pada endotel melalui pengeluaran katekolamin dan mempermudah penggumpalan darah sehingga menimbulkan terjadinya peningkatan denyut jantung dan tekanan darah. Selain itu, kandungan karbon monoksida (CO) pada rokok dapat menimbulkan desaturasi hemoglobin yang menurunkan persediaan oksigen untuk jaringan termasuk miokard. Hasil dari penelitian ini sejalan dengan penelitian dari Yuliani, Oenzil, \& Iryani (2014) bahwa risiko terjadinya PJK meningkat dua kali lipat pada perokok. Hasil Penelitian Yuliani, Oenzil dan Iryani (2014) menyimpulkan bahwa terdapat hubungan yang sangat bermakna $\quad(p<0,0001)$ antara jenis kelamin, dislipidemia, dan merokok dengan kejadian PJK pada penderita DM tipe 2. Hasil ini semakin menunjukkan bahwa merokok sangat berisiko pada terjadinya PJK.
Menurut asumsi peneliti selama melakukan penelitian di poliklinik RS Panti Rapih perawat yang bertugas bersama dokter sudah memberikan edukasi tentang bahaya dalam merokok namun belum ada waktu khusus dalam melakukan edukasi kepada pasien, dengan diberikan edukasi tersebut diharapkan jumlah perokok dapat berkurang sehingga jumlah penderita PJK juga berkurang. Namun dilihat dari hasil penelitian yang dilakukan oleh peneliti menyatakan bahwa sebagian besar penderita PJK di RS Panti Rapih faktor risikonya adalah merokok, maka perawat perlu meningkatkan promosi kesehatan bersama tenaga kesehatan yang lain dan masyarakat luas tentang bahaya dan dampak merokok.

\section{b. Hipertensi}

Berdasarkan penelitian lebih dari separuh yaitu sejumlah 34 responden (68\%) dengan PJK memiliki riwayat hipertensi. Hipertensi dikatakan berisiko karena tekanan darah yang tinggi secara terus menerus menyebabkan 
kerusakan sistem pembuluh darah arteri dengan perlahan-lahan. Arteri tersebut mengalami pengerasan yang disebabkan oleh endapan lemak pada dinding arteri, sehingga menyempitkan lumen yang terdapat di dalam pembuluh darah.

$$
\text { Dilakukannya banyak }
$$

penelitian yang berhubungan dengan hipertensi, hampir semuanya menemukan bahwa semakin tinggi tekanan darah seseorang, maka semakin tinggi risiko terkena PJK (Amiruddin, Danes, \& Lintong, 2015).

Menurut peneliti, perawat sangat menentukan dalam pencegahan terjadinya PJK pada pasien. Perubahan gaya hidup juga sangat dianjurkan untuk pasien hipertensi, untuk itu perlu adanya waktu khusus antara perawat dan pasien agar perawat dapat memberikan edukasi yang dapat diterima dan dipahami oleh pasien.

\section{c. Diabetes Melitus}

Berdasarkan hasil penelitian ini, kurang dari separuh yaitu sejumlah 14 responden (28\%) dengan PJK memiliki riwayat diabetes melitus. Diabetes mellitus dikatakan berisiko karena kelainan lipid (hipertrigliseridemia, kolesterol HDL rendah, serta kadang _ _ kadang hiperkolesterolemia). Kadar gula darah yang normal cenderung meningkat secara ringan, tetapi progresif setelah usia 50 tahun, terutama pada orang-orang yang tidak aktif, kadar gula darah meningkat mengakibatkan darah menjadi pekat dan terjadi pengendapan atheoschlerosis pada arteri coroner (Nugroho, 2008).

Seseorang yang menderita DM menurut Nababan (2008) berisiko mendapatkan komplikasi kronik salah satunya adalah PJK. DM merupakan faktor risiko yang sangat kuat, sehingga seorang penderita DM sering sudah dianggap menderita penyakit jantung koroner.

Kontrol glikemia jelas menurunkan komplikasi mikrovaskuler pada pasien diabetes. Untuk itu, perawat perlu melakukan edukasi kepada pasien tentang manfaat mengontrol gula 
Faktor Risiko Terjadinya Penyakit Jantung Koroner pada Pasien di Unit Rawat Jalan Rumah Sakit Panti Rapih Yogyakarta

darahnya. Sejauh ini, peneliti melihat di RS Panti Rapih para perawat sudah melakukan edukasi kepada pasien, hanya saja dalam memberikan edukasi belum maksimal dikarenakan tidak ada waktu khusus antara perawat dan pasien sehingga dalam memberikan edukasi hanya seperlunya saja. Hasil Penelitian Yuliani, Oenzil dan Iryani (2014) menyimpulkan bahwa terdapat hubungan yang sangat bermakna $(p<0,0001)$ antara jenis kelamin, dislipidemia, dan merokok dengan kejadian PJK pada penderita DM tipe 2 dan terdapat hubungan yang bermakna $(p<0,05)$ antara lama menderita DM, hipertensi, obesitas dengan kejadian PJK pada penderita DM tipe 2. Hasil ini menunjukkan bahwa penyakit DM merupakan faktor risiko terjadinya PJK tetapi berbeda dengan penelitian ini karena hanya $28 \%$ yang menderita DM. Hal ini dapat dimungkinkan karena responden dalam penelitian ini juga menderita hipertensi. d. Dislipidmia

Berdasarkan penelitian ini sebagian besar sejumlah 45 responden (90\%) dengan PJK memiliki dislipidmia tinggi. Hampir seluruh responden dalam penelitian ini berisiko terhadap PJK akibat dari konsumsi lemak berlebih untuk tubuh, sehingga menyebabkan penumpukan lipid di dinding pembuluh darah (plak/trombus). Trombus tersebut menyebabkan terjadinya penyempitan dan pengerasan di pembuluh darah arteri koroner yang disebut dengan atherisclerosis. Seseorang dengan dislipidmia menurut Oktavitasari, Hamzah, \& Muhsinin (2016) biasanya dilatarbelakangi kebiasaan dalam mengkonsumsi makanan berlemak. Selain itu peneliti juga mengasumsikan bahwa sesorang memiliki dislipidmia tinggi dikarenakan kurangnya pengetahuan akibat dari konsumsi lemak yang berlebihan.

e. Berat Badan Berlebih

Berdasarkan penelitian kurang dari separuh sejumlah 21 
responden (42\%) memiliki BMI $\geq 25$. Pengaruh kegemukan pada PJK tidak selalu berdiri sendiri, tetapi umumnya diperburuk oleh faktor risiko lain seperti hipertensi, diabetes dan hiperlipidmia. Seseorang dengan berat badan berlebih atau $\mathrm{BMI} \geq 25$ menurut Supriyono (2008) berisiko tinggi terhadap PJK. Menurut penelitian yang dilakukan oleh Okvitasari, Hamzah, \& Muhsinin (2016) berat badan merupakan faktor risiko kekambuhan PJK yang sulit diturunkan, karena berkaitan dengan kebiasaan pola makan, olah raga dan lainnya. Seseorang yang ingin menurunkan berat badan agar dapat ideal/ normal harus benar-benar disiplin dengan pola makannya dengan tetap memperhatikan prinsip-prinsip kecukupan gizi. Dalam hal ini sebagai pelopor kesehatan, perawat perlu mendukung dan mengedukasi pasien agar tetap patuh terhadap dietnya dan menjaga pola makan yang sehat.

$$
\text { Dalam }
$$

melakukan

penelitian ini, terdapat keterbatasan yaitu responden dalam penelitian ini dalam menjawab kuisioner tentang pertanyaan berat badan dan tinggi badan sebelum terdiagnosa PJK yang diberikan oleh peneliti hanya mengkira - kira saja dengan alasan lupa. Jadi, perhitungan BMI sebagai penentu faktor risiko PJK belum tentu sesuai dengan kejadian yang dialami responden saat itu. Peneliti berharap dalam penelitian selanjutnya dapat mengidentifikasi tentang berat badan dan tinggi badan responden sebelum terdiagnosa PJK sebagai faktor risiko dengan tepat sehingga perhitungan BMI dapat sesuai dengan kejadian yang sebenarnya saat itu.

\section{f. Kurang Aktivitas Fisik}

Berdasarkan penelitian dari separuh sejumlah 19 responden (38\%) dengan PJK kurang melakukan aktivitas fisik yang menyehatkan badan seperti olahraga. Kurang aktivitas fisik dikatakan berisiko karena dalam upaya untuk mencegah proses aterosclerosis dan PJK akibat tingginya hiperlipidmia, perlu 
dilakukan pengontrolan dan mengusahakan agar kadar tersebut dalam batas aman. Salah satunya adalah dengan latihan fisik/olahraga yang teratur dan terencana dengan baik.

Sejalan dengan penelitian yang dilakukan oleh Nababan (2008) bahwa semakin lama seseorang berolahraga maka semakin banyak pula darah yang dialirkan sehingga semakin banyak oksigen yang dipakai dan didistribusikan ke jantung dan ke seluruh tubuh. Sebaliknya jika seseorang kurang melakukan aktivitas fisik yang menyehatkan badan seperti berolahraga maka proses aterosclerosis tidak dapat dicegah akibat tingginya hiperlipidmia.

\section{Manfaat olahraga banyak} sekali membantu membakar kalori, meningkatkan jumlah reseptor insulin pada dinding sel, memperbaiki sirkulasi darah dan menguatkan otot jantung, mengurangi kadar kolesterol, membantu melepaskan kecemasan, stres dan ketegangan sehingga memberikan rasa sehat dan bugar
(Okvitasari , Hamzah, \& Muhsinin, 2016).

\section{KESIMPULAN DAN SARAN}

\section{Kesimpulan}

Berdasarkan hasil penelitian yang dilakukan, kesimpulan yang didapatkan adalah sebagai berikut:

1. Faktor risiko yang tidak dapat diubah didapatkan hasil sebagai berikut sebanyak sejumlah 21 responden $(42 \%)$ yang memiliki riwayat keluarga dengan PJK, sejumlah 36 responden (95\%) memiliki usia berisiko yaitu $\geq 40$ tahun untuk pria. Sedangkan pada wanita sebanyak sejumlah 7 responden (95\%) memiliki usia berisiko $\geq 65$ tahun, sejumlah 38 responden (76\%) dengan PJK berjenis kelamin laki - laki.

2. Faktor risiko yang dapat diubah didapatkan hasil sebagai berikut sejumlah 39 responden (78\%) dengan kebiasaan merokok, sejumlah 34 responden (68\%) dengan riwayat hipertensi, sejumlah 14 responden (28\%) dengan diabetes mellitus, 
sejumlah 45 responden (90\%) dengan dislipidmia tinggi, sejumlah 21 responden $(42 \%)$ dengan berat badan berlebih, dan sejumlah 19 responden $(38 \%)$ kurang memiliki aktivitas yang menyehatkan badan seperti olahraga.

\section{Saran}

1. Bagi Perawat

a. Diharapkan mampu mengenal, menggali dan mengidentifikasi lebih dalam terkait faktor risiko terjadinya PJK, sehingga dapat memberikan edukasi bagi penderita maupun yang berisiko lebih awal untuk mengurangi angka kejadian PJK.

b. Diperlukan adanya promosi kesehatan secara komprehensif dan ada ruang serta waktu khusus pada kelompok dewasa tentang peningkatan kualitas hidup melalui perilaku hidup sehat dan menghindari faktor risiko terjadinya $\mathrm{PJK}$.
2. Bagi Peneliti Selanjutnya

Diharapkan peneliti selanjutnya mampu untuk melaksanakan penelitian secara lebih mendalam dengan jumlah sampel yang lebih banyak lagi sehingga hasil penelitian akan lebih baik dan lebih valid, selain itu dapat pula meneliti tentang bagaimana perilaku pasien dengan PJK setelah mengetahui faktor-faktor risiko terjadinya PJK.

\section{DAFTAR PUSTAKA}

Amiruddin, M. A., Danes, V. R., \& Lintong, F. (2015). Analisa hasil pengukuran tekanan darah antara posisi duduk dan posisi berdiri pada mahasiswa semester vii (tujuh) Ta. 2014/2015 Fakultas Kedokteran Universitas Sam Ratulangi. jurnal e-Biomedik, 125-129. Diambil kembali dari http://www.ejournal.unsrat.ac. id/imdex.php/ebiomedik/artic le/view/6635.

Andarmoyo, S., \& Nurhayati, T. (2014). LAKI-LAKI DAN RIWAYAT KELUARGA DENGAN PENYAKIT JANTUNG KORONER (PJK) BERESIKO TERHADAP KEJADIAN 
Faktor Risiko Terjadinya Penyakit Jantung Koroner pada Pasien di Unit Rawat Jalan Rumah Sakit Panti Rapih Yogyakarta

PJK. Diambil dari: https://www.semanticscholar. org/paper/LAKI-LAKIDAN-RIWAYATKELUARGA-DENGANPENYAKIT-PJK-

AndarmoyoNurhayati/9a4755a2a18f57d $\underline{66 \mathrm{ba} 2 \mathrm{e} 6684 \mathrm{de} 27 \mathrm{~d} 70098 \mathrm{~b} 78 \mathrm{a}}$ f.

Hurst, M. (2016). Belajar mudah keperawatan medikal-bedah vol 1. Jakarta: EGC.

Nababan, D. (2008). Faktor Risiko PJK. Hubungan faktor risiko dan karakteristik penderita dengan kejadian penyakit jantung, 40.

Nugroho, Hidlider. (2008). Mengenali Penyakit Jantung Koroner. Tanpa Kota: Istira.

Oktavitasari, Y., Hamzah, \& Muhsinin. (2016). Faktor Risiko PJK. Analysis of factors related to the occurrence of coronary heart disease at heart polyclinic ulin hospital, 17. Diambil kembali dari http://www.journal.stikesmb.ac.id/index.php/caring/artic le/view/.

Riskesdas. (2013). Riset Kesehatan Dasar. Diambil kembali dari http://www.depkes.go.id/reso urces/dowload/general/Hasil \%20Riskesdas\%202013.pdf.

Riskesdas. (2018). Riset Kesehatan Dasar. Diambil kembali dari http://www.kesmas.kemkes.g o.id/assets/upload/dir 519d4
$1 \mathrm{~d} 8 \mathrm{~cd} 98 \mathrm{f} 00 /$ files/Hasilriskesdas-2018 1274.pdf.

Robinson, J. M., \& Saputra, L. (2014). Buku ajar : visual nursing, jilid satu. Tangerang Selatan: BINAPURA

AKSARA Publisher.

Sanchis-Gomar, F., Perez-Quilis, C., Leischik, R., \& Lucia, A. (2016). Epidemiology of coronary heart disease and acute coronary syndrome. Annals of translational

medicine, 4(13), 256. https://doi.org/10.21037/atm. 2016.06.33.

Supranto. (2009). Statistik Pengukuran Instrumen Penelitian: ECG.

Supriyono, M. (2008). Faktor faktor risiko yang berpengaruh terhadap kejadian penyakit jantung koroner pada kelompok usia kurang dari 45 tahun, 24-40. Diambil kembali dari http://www.eprints.undip.ac.i $\mathrm{d} / 18090 /$.

Yuliani, F., Oenzi, F dan Iryani, D. (2014). Hubungan Berbagai Faktor Risiko Terhadap Kejadian Penyakit Jantung Koroner Pada Penderita Diabetes Melitus Tipe 2. Vol 3, No 1.

Zahrawardani, D., Herlambang, K. S., \& Anggraheny, H. D. (2013). Analisis faktor resiko kejadian penyakit jantung 
Jurnal Keperawatan I CARE, Vol. 1 No. 1 Tahun 2020

koroner di RSUP Dr Kariadi

Semarang, Jurnal Kedokteran Muhammadiyah Volume 1

Nomor 2 Tahun 2013. 